Copyright (C) 2014 IEEE. Personal use of this material is permitted. Permission from IEEE must be obtained for all other uses, in any current or future media, including reprinting/republishing this material for advertising or promotional purposes, creating new collective works, for resale or redistribution to servers or lists, or reuse of any copyrighted component of this work in other works. 


\title{
Data Communication Network and its Delay Effect on the Dynamic Operation of Distributed Generation Units in a Microgrid
}

\author{
Made Andik Setiawan ${ }^{1,2}$, Farhad Shahnia ${ }^{2}$, Ruwan P.S. Chandrasena ${ }^{2}$, and Arindam Ghosh ${ }^{2}$ \\ ${ }^{1}$ Politeknik Manufaktur Negeri Bangka Belitung, Sungailiat, Indonesia \\ ${ }^{2}$ Electrical and Computer Engineering Department, Curtin University, Perth, Australia \\ i.setiawan@postgrad.curtin.edu.au
}

\begin{abstract}
A three-level hierarchical control system is considered for microgrids. The microgrid central controller receives the desired ratio for the output power of the available distributed generation units (DG) from the network tertiary controller. It then passes this information to the primary controller of each DG in the form of setpoints. In addition, the central controller receives some information from the DGs or the network and considers them to adjust the setpoints for the DGs. In this paper, the effect of the data transfer delays in the communication system of future microgrids is investigated on the dynamic operation of the distributed energy resources.
\end{abstract}

Index Terms-Communication System, Data Management Scheme, Data Transmission Delay, Microgrid, ZigBee.

\section{INTRODUCTION}

The increasing number of renewable energy sources such as photovoltaic, wind and micro-hydro are leading to a substantial amount of electric energy generation in the form of distributed generation units (DG) within the electric networks. Microgrid (MG) is a cluster of loads, DGs and energy storages interconnected by a network of feeders and located in the same geographical area which can act as an independent power system whenever needed [1]. In the presence of a main utility grid, MG can operate either in grid-connected mode or in off-grid mode. In grid-connected mode, the network voltage and frequency are dictated by the grid; hence the DGs are controlled such that the desired amount of power (based on maximum power point tracking or economic power dispatch) is supplied by each DG. Hence, any power mismatch between the generated power by the DGs and the load requirement will be met by the grid. In off-grid mode, the DGs are not only required to supply the MG load demand but also they should regulate the voltage and frequency within the acceptable limits. Therefore, for proper operation and control of DGs within the MG, each DG should be updated with the information about the MG operation mode. This information is required to be transferred from the $\mathrm{MG}$ main Circuit Breaker (CB), which interconnects the MG and the grid (as shown in Fig. 1), to all the DGs.

Additionally, the MG requires the real-time power meas-

This research was financially supported by Lembaga Pengelola Dana Pendidikan (LPDP), Ministry of Finance, Indonesia.

978-1-4799-7537-2/14/\$31.00 @2014 IEEE

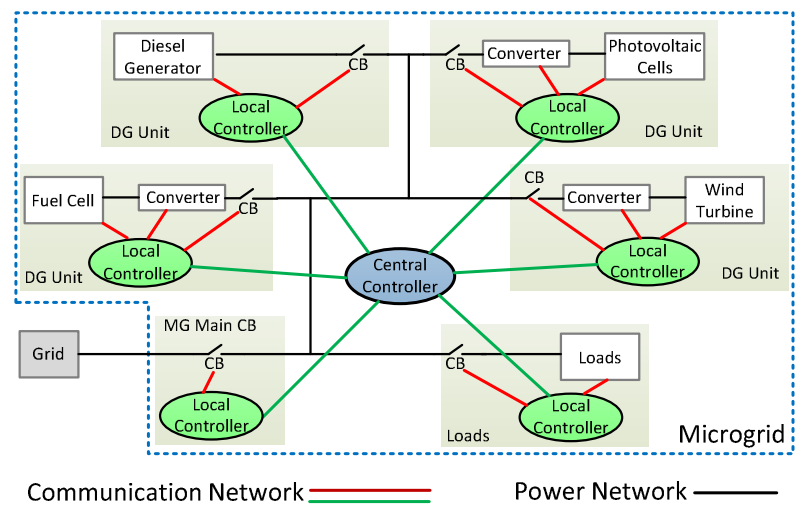

Fig. 1. Schematic of a MG system.

urement of the grid, loads and DGs as well as the state of charge of the available storage devices. Similarly, the rms value, phase angle and frequency of voltage as well as the active/reactive power flows at certain specific points in the MG are required to be monitored and utilized as inputs to the control system of the DGs. Furthermore, instantaneous values of voltages at the terminals of DGs and the line are needed during synchronization of a new DG with the MG. Fig. 1 shows a sample MG network along with the different data which need to be monitored and transmitted to the respective controllers. Therefore, MGs need a fast and accurate data transmission system to transfer the measured data and command signals to the relevant controllers in the DG or the MG. Hence, a proper Information and Communication Technology (ICT) needs to be developed [2]. This facilitates controlling and monitoring of electricity generation and consumption as well as network remote operation. Wired and wireless communication technologies can be employed in MGs. The popular wired technologies used in power systems, are serial communication RS-232/422/485, bus technology (e.g. ModBus, ProfiBus, CANBus) [3], power-line communication (e.g. PLC, BPLC) [2], and Ethernet (e.g. LAN, optical cable) [3,4]. On the other hand, the popular wireless technologies, used in power systems, are cellular (e.g. GSM, CDMA) [4], Wi-Fi [5,6], WiMax [7], ZigBee [8-10], Z-Wave [11], Bluetooth [9], Insteon [12], radio frequency [9] and Microwave [12].

The wired technologies have higher data transfer bandwidth and are more reliable; however their installation cost is very high. On the other hand, the wireless technologies have less installation costs compared to the wired technologies and 
are more suitable for remote areas while being more flexible for future expansions [9]. A comparison among different wireless technologies that can be considered for MG applications is presented in Table I.

By the growing number of meters, sensors and actuators which need to be monitored and controlled continuously within a MG, utilizing wired technologies leads to a significant installation cost. Therefore, the wireless technologies are a better candidate for MG applications. However, it is to be noted that they have a lower data transmission rate and can be vulnerable to interferences with other signals [6].

\section{COMMUNICATION LAYERS IN MiCROGRIDS}

A hierarchical control system is usually required for the proper operation and control of the MG, as discussed below.

a) The local (primary) controller: This controller is the lowest control block within the hierarchical control system and is located within every DG unit. This controller mainly controls the operation of a DG based on local measurements. Hence, it fetches data from the local sensors/meters using very small sampling time steps and produces the required outputs for the DG actuators.

b) The MG central controller: This is the main controller for the MG and is mainly responsible for controlling the volt age magnitude and frequency in the MG. This controller receives the voltage magnitude and frequency data from the local controllers and sends back the proper reference for voltage magnitude and frequency in each DG. This controller has a larger time step in comparison to the local controllers.

c) The network tertiary controller: This controller is at the highest level in the hierarchical control system and is responsible for general control of the power network. This controller can have several modules such as load forecast, electricity market, self-healing, unit-commitment, economic dispatch, etc. This controller defines if a MG should be operating in grid-connected or islanded mode, the output power of each DG unit, the interconnection of two neighboring MGs, etc. Therefore, for providing a proper data transmission network among the three controllers, discussed above, in a hierarchical control system, a communication network and associated technical infrastructure are required.

To provide a proper data transmission network among the three hierarchical controllers, a communication network and associated technical infrastructure are required. To transfer these data to the MG central controller, several parameters should be considered in selecting and designing the communication technology. They are:

- The size of the area in which the MG is distributed

- Installation, operational and maintenance costs

- Number of sensors, actuators, meters or devices

- Minimum data transmission rate requirement

- Data precision requirement

- Maximum data packet error requirement

- Flexibility to future expansions

- Availability of different techniques to access the data

Based on the location of the communication devices as well as the characteristics of the data to be transferred, the

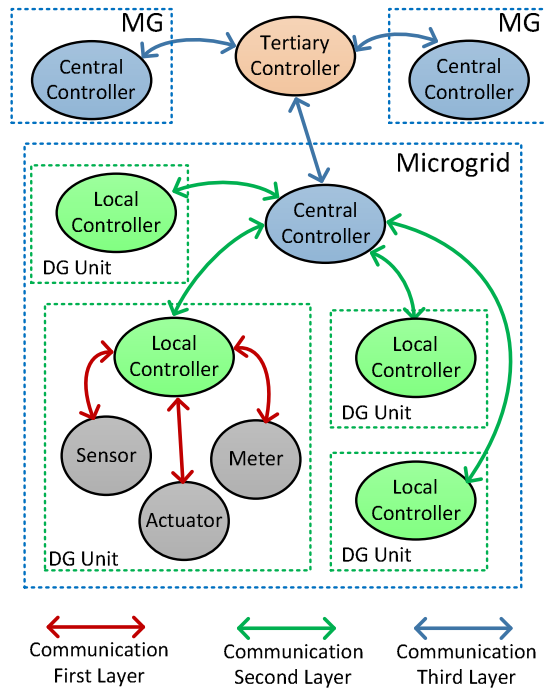

Fig. 2. Proposed hierarchical communication layer in MG.

Table 1. Comparisons of different wireless technologies applicable for MGs

\begin{tabular}{|c|c|c|c|c|c|}
\hline Technology & Range & $\begin{array}{l}\text { Data } \\
\text { Rate }\end{array}$ & Frequency & $\begin{array}{l}\text { Suitable } \\
\text { for }\end{array}$ & $\begin{array}{l}\text { Installation } \\
\text { Cost }\end{array}$ \\
\hline $\begin{array}{l}\text { Cellular } \\
\text { (GSM, } \\
\text { CDMA) }\end{array}$ & $\begin{array}{l}\text { several } \\
\mathrm{km}\end{array}$ & $\begin{array}{l}270 \\
\text { kbps }\end{array}$ & $\begin{array}{l}900,1800 \\
\mathrm{MHz}(2 \mathrm{G}), \\
2.1 \mathrm{GHz}(3 \mathrm{G})\end{array}$ & backbone & Costly \\
\hline WiFi & $100 \mathrm{~m}$ & $\begin{array}{l}54 \\
\text { Mbps }\end{array}$ & $2.4 \mathrm{GHz}$ & backbone & moderate \\
\hline WiMax & $\begin{array}{l}\text { several } \\
\mathrm{km}\end{array}$ & $\begin{array}{l}30- \\
40 \\
\text { Mbps }\end{array}$ & $\begin{array}{l}2.3,2.5,3.5 \\
\mathrm{GHz}\end{array}$ & backbone & moderate \\
\hline ZigBee & $\begin{array}{l}100- \\
1500 \mathrm{~m}\end{array}$ & $\begin{array}{l}250 \\
\text { kbps }\end{array}$ & $\begin{array}{l}2,4 \mathrm{GHz}, \\
868,915 \\
\mathrm{MHz}\end{array}$ & $\begin{array}{l}\text { end de- } \\
\text { vices }\end{array}$ & low \\
\hline Z-Wave & $30 \mathrm{~m}$ & $\begin{array}{l}100 \\
\text { kbps }\end{array}$ & $900 \mathrm{MHz}$ & $\begin{array}{l}\text { end de- } \\
\text { vices }\end{array}$ & low \\
\hline Insteon & $50 \mathrm{~m}$ & $\begin{array}{l}38 \\
\text { kbps }\end{array}$ & $900 \mathrm{MHz}$ & $\begin{array}{l}\text { end de- } \\
\text { vices, } \\
\text { backbone }\end{array}$ & low \\
\hline Bluetooth & $100 \mathrm{~m}$ & $\begin{array}{l}24 \\
\text { Mbps }\end{array}$ & $2.4 \mathrm{GHz}$ & $\begin{array}{l}\text { end de- } \\
\text { vices, } \\
\text { backbone }\end{array}$ & low \\
\hline
\end{tabular}

communication technologies in the MG are classified as the following three layers, as shown schematically in Fig. 2.

The first communication layer provides data transfer capability among the local controller of each DG to the sensors, meters and actuators of the DG. In addition, the transfer of data from any meters/sensors installed along the power distribution lines or CBs to their local controllers also falls within this layer. The second communication layer provides data transfer capability among the local controllers of the DGs and the MG central controller. This layer is the main communication layer of the MG. The third communication layer is used to provide data transfer within a group of neighboring MGs [13-15] This layer transfers data between the central controllers of the MGs and the electric network tertiary controller. This paper focuses on the second communication layer of the MG only.

\section{ZigBeE COMMUNICATION IN MicRogRIDS}

ZigBee is an emerging wireless communication technology. It can connect directly to sensors, meters and actuators. In 
addition, it is a low-cost and low-power device which has less complexity for the users and is also flexible for expansion in future $[9,14]$. Based on IEEE Std. 802.15.4, ZigBee has data transfer rate up to $250 \mathrm{kbps}$. In addition, it is a low consumption device and hence, it can operate for a long time with only AA batteries [10]. On the other hand, ZigBee is a short range wireless communication device which can cover an area of around 300-1500 $\mathrm{m}$ [16].

In terms of communication capabilities, there are two types of ZigBee devices, i.e. Full Function Device (FFD) and Reduced Function Device (RFD) [17]. An RFD has the capability to connect to sensors, actuators and meters; however, it does not have the capability to communicate with other RFDs. On the other hand, an FFD has the capability to communicate with other FFDs as well as the sensors, actuators and meters [17]. The RFD acts as a ZigBee end-device, whereas the FFD can act as a router or a coordinator. The router is used for data routing, communicating with other routers or coordinators, extending the covered area as well as strengthening the transmitted signals [10]. The coordinator is used to establish and manage the network.

The sensors/meters/actuators in one DG can be connected directly to the local controller through either of Analog-toDigital Converters (ADC), General Purpose Input-Output (GPIO) or serial communication. The received data and any processed outputs can then be transmitted by the RFD, which is connected to the local controller. The transmitted data by the local controller of the DG will be received by the MG central controller through the FFD. This is shown in Fig. 3(a).

Alternatively, the sensors/meters/actuators can be connected directly to a RFD which transmits data to the MG central controller. This is applicable for measurements from the $\mathrm{CB}$ and power distribution lines where no significant computation and control process is required. This is shown in Fig. 3(b).

The communication between the FFD/RFDs and the coordinator (in non-beacon network) starts by the coordinator requesting data from the FFD/RFDs. Then, the RFD/FFDs confirm by transmitting an ACK and the requested data. After receiving the data, the coordinator transmits the acknowledge frame to the FFD/RFDs. The schematic of this communication sequence is illustrated in Fig. 4.

The number of the data to be monitored and transferred in an MG depends on the number of the DGs within the MG. In addition, some DGs might have a particular set of data to be monitored and transmitted such as the weather data. Consequently, the number of data to be transferred in the MG can be very large. Since the data rate of ZigBee is only up to 250 $\mathrm{kbps}$, the data transmission in MGs should be carefully managed such that the network bandwidth can handle the data transactions.

Based on IEEE Std. 802.15.4, ZigBee devices are available with $868 \mathrm{MHz}, 915 \mathrm{MHz}$ and $2.45 \mathrm{GHz}$ carrier frequencies. The lower carrier frequency usually has longer area coverage, e.g. the $2.45 \mathrm{GHz}$ ZigBee from the Xbee-Pro from Digi International Inc. can cover an area up to $1.5 \mathrm{~km}$, while the 868 and $915 \mathrm{MHz}$ ZigBees from the same manufacturer can cover an area up to 40 and $14.5 \mathrm{~km}$, respectively [16].

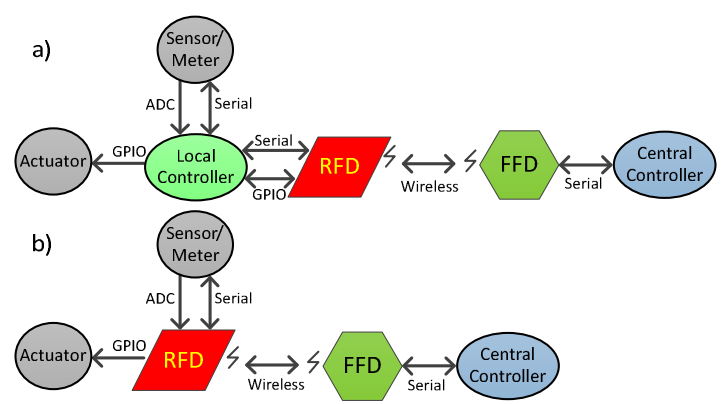

Fig. 3. FFD and RFD utilization in the MG:

a) $\mathrm{DG}$ local controller connection to $\mathrm{MG}$ central controller,

b) $\mathrm{CB}$ status and voltage/frequency data transfer to central controller.

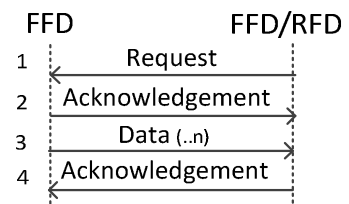

Fig. 4. Schematic of data request, transfer and acknowledgement between the FFD/RFD and the coordinator.

The data to be transferred should be coded such that it represents data type (i.e. voltage magnitude, voltage angle, active power, reactive power, frequency and CB status), data dimension (e.g. kilo, mega), data value (e.g. 220), RFD or FFD number, Channel number (if there is more than one sensor/actuator/meter connected to a single RFD) and DG number in MG. All these data need to be mapped into data payload section which maximum of 888 number of bits [17].

As an example, to transmit the voltage magnitude of 220 $\mathrm{V}$, measured in the MG, from RFD to FFD using $2.45 \mathrm{GHz}$ ZigBee, first the 220 decimal digits need to be coded into binary digit (i.e. 1101 1100). Then, the binary digit should be mapped into symbol and each symbol to be mapped into chipPN sequence. Fig. 5 shows schematically the data modulation processes from binary digit into a symbol and then into chipPN sequence before spreading in the form modulated signal converted into binary code and then converted into a symbol.

\section{DATA TRANSMISSION DELAY}

The time to transfer each bit by ZigBee devices depends on the data transfer rate. This time can be calculated as $T_{B i t}=$ 1 data rate. Hence, $T_{B i t}$ is equal to 4,25 and $50 \mu$ s for the 2.45 $\mathrm{GHz}, 915 \mathrm{MHz}$ and $868 \mathrm{MHz}$ ZigBee devices, respectively.

The required time to transfer a symbol $\left(T_{\text {Symbol }}\right)$ can be calculated as $T_{\text {Symbol }}=T_{\text {Bit }} \times$ number of bits in each symbol. Hence, $T_{\text {Symbol }}$ of $2.45 \mathrm{GHz}$ ZigBee is $T_{\text {Bit }} \times 4$ bits $=16 \mu \mathrm{s}$; however, $T_{\text {Symbol }}$ when using $915 \mathrm{MHz}$ and $868 \mathrm{MHz}$ ZigBees are respectively $T_{B i t} \times 1$ bits $=25 \mu$ s and $T_{B i t} \times 1$ bits $=50 \mu \mathrm{s}$.

The total processing time for the data payload $\left(T_{\text {DataPayload }}\right)$ is calculated as

$T_{\text {DataPayload }}=T_{\text {Symbol }} \times$ ceiling $\left(\frac{\text { numberof binarydigits }}{\text { numberof bitsin each symbol }}\right)$

where the number of bits for a symbol is 4 bits for $2.45 \mathrm{GHz}$ ZigBee and one bit for 915 and $868 \mathrm{MHz}$ ZigBees. 
As an example, the processing time of transmitting the data payload of $220 \mathrm{~V}$, for ZigBees with different carrier frequencies and different formats are listed in Table 2.

Assuming minimum number of bits is used for the address fields (i.e. 32 bits based on [17]), the total processing time for transferring the Data Frame $\left(T_{\text {DataFrame }}\right)$ is calculated as:

$T_{\text {DataFrame }}=T_{\text {DataPayload }}+T_{D F}$

where $T_{D F}$ is the processing time for the other sections of the Data Frame (i.e. preamble sequence, start of frame delimiter, frame length, frame control, sequence number, addressing field and frame check sequence sections). $T_{D F}$ is 480,3000 and frame length, frame control, sequence number, addressing field and frame check sequence sections). $T_{D F}$ is 480 , 3000 and $6000 \mu \mathrm{s}$ respectively for $2.45 \mathrm{GHz}, 915$ and 868 $\mathrm{MHz}$ ZigBee. After a successful data transaction, the receiving FFD sends an Acknowledgement Frame. The processing time of an ACK is 352,2200 and $4400 \mu$ s respectively for $2.45 \mathrm{GHz}, 915$ and $868 \mathrm{MHz}$ ZigBees.

The complete data transmission in ZigBee is started by transmitting the Data Frame by the transmitter followed by an Acknowledgement Frame received from the receiver. The receiver sends back the Acknowledgement Frame after a period of $12 T_{\text {Symbol }}$. The waiting time since the data is fully transmitted until receiving the Acknowledgement Frame has a maximum of $54 T_{\text {Symbol }}[17]$. The successful data transmission in Zigbee is illustrated as shown in Fig. 6(a).

If the transmitter does not receive any an Acknowledgement Frame within this period, it resends the Data Frame to the receiver again. The transmitter will retry to transmit this data maximum of 3 times [17]. If the transmitter still does not receive an Acknowledgement Frame, it generates a MLMECOMM-STATUS indication with a status of NO_ACK [17]. The unsuccessful data transmission in Zigbee is illustrated as shown in Fig. 6(b).

\section{Microgrid StRUCTURE UNDER CONSIDERATION}

Let us consider the MG structure of Fig. 7 with 2 converterinterfaced DGs and 2 distributed loads. The DGs are connected through voltage source converters (VSC) and properly tuned filters to the network. DGs are controlled to supply the load requirements within the MG, when the microg. The detailed discussion on the DG type, VSC and filter structure and its control system is discussed in detail in [13]. Since it is beyond the scope of this paper, it is not repeated here. It is to be noted that the considered DG systems in this paper are working in voltage control mode based on droop and their instantaneous output power, are within their maximum capacities. When the MG is in grid-connected mode, the DGs operate at their maximum power point conditions. However, as the MG falls into autonomous mode, the status of the MG main CB should be transferred to each DG to change its mode of operation. The output power of the DGs are controlled by $P-\delta$ and $Q-V$ droop equations of

$\delta=\delta_{\text {rated }}+m\left(P_{\text {rated }}-P\right), \quad|V|=V_{\text {rated }}+n\left(Q_{\text {rated }}-Q\right)$ (a) Data $\stackrel{\text { Binary digit }}{22 \mathrm{O}_{10}} \rightarrow 1101 \mathrm{IIOO}_{2}$

(b)

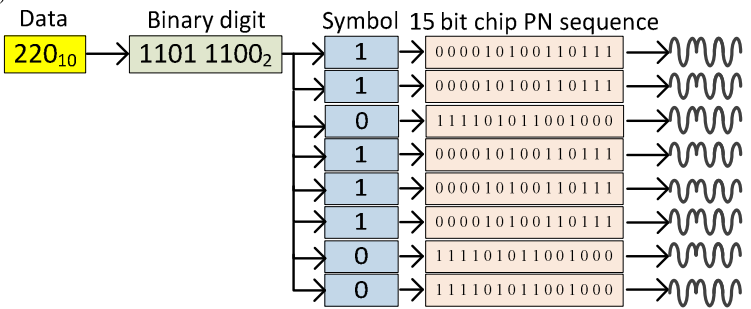

Fig. 5. An example illustrating the steps of modulating $220 \mathrm{~V}$ in ZigBee, (a) for $2.45 \mathrm{GHz} \mathrm{ZigBee}$, (b) for 868 or $915 \mathrm{MHz} \mathrm{ZigBee}$.
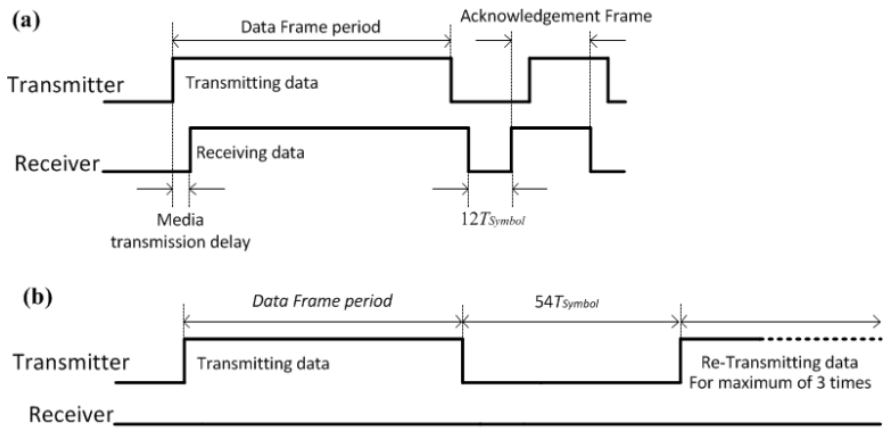

Fig. 6. Schematic representation of data transmission in ZigBee: (a) Successful data transaction, (b). unsuccessful data transaction.

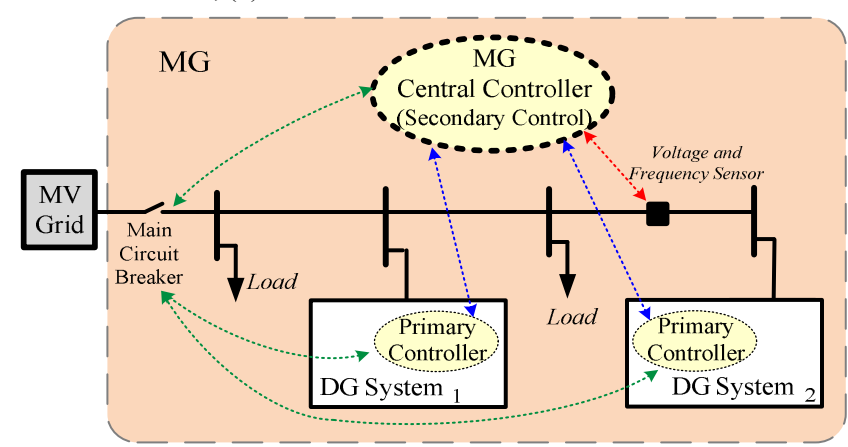

Fig. 7. Schematic diagram of the $\overline{M G}$ network under consideration along with its hierarchical control system.

Table 2. Numerical comparison of data processing time [ms] when using ZigBees with different carrier frequencies and different formats

\begin{tabular}{ll}
\hline$T_{\text {DataPayload }}$ & Binary Format \\
\hline $2.45 \mathrm{GHz}$ & $16 \mu \mathrm{s} \times$ ceiling $(26 / 4)=0.112 \mathrm{~ms}$ \\
$915 \mathrm{MHz}$ & $25 \mu \mathrm{s} \times 26$ bits $=0.65 \mathrm{~ms}$ \\
$868 \mathrm{MHz}$ & $50 \mu \mathrm{s} \times 26$ bits $=1.3 \mathrm{~ms}$ \\
\hline
\end{tabular}

where $|V|$ and $\delta$ are respectively the magnitude and angle of the voltage at the output of VSC, $P$ and $Q$ are respectively the average active and reactive at the DG connection point to the network, $m$ is the coefficient of the $P-\delta$ droop equation and $\mathrm{n}$ is the coefficient of the $Q-V$ droop equation. The suffix rated shows the reference values for each of the parameters.

In [15] it is shown that for a proper power sharing ratio control among parallel DGs in an autonomous MG, it is required to satisfy the following equations:

$\frac{P_{2}}{P_{1}}=\frac{P_{\text {rated }, 2}}{P_{\text {rated }, 1}}=\frac{m_{1}}{m_{2}} \quad, \quad \frac{Q_{2}}{Q_{1}}=\frac{Q_{\text {rated }, 2}}{Q_{\text {rated }, 1}}=\frac{n_{1}}{n_{2}}$ 
As the network load is varied, the DGs automatically adopt their output power to supply the new load demand of the system. Hence, the voltage and frequency of the network is indirectly regulated by (4).

If the network voltage and frequency fall beyond the acceptable pre-defined limits, the MG central controller will take action and adjust the set points of the droop controller for each DG. This process required a data transfer between the voltage and frequency meters in the networks to the $\mathrm{MG}$ central controller and from the central controller to the primary controllers of each DG. The new set points calculation analysis presented in [18] and since it falls beyond the scope of this paper, it is not repeated here.

\section{COMmunication Delay EFFeCtS}

The MG system of Fig. 7 is simulated in PSCAD/EMTDC with several assumptions. Several load changes are applied to the system. Following any load change, the DGs need to update their output power accordingly. As the result of any load change, the voltage magnitude and frequency will be affected. If these values fall beyond the acceptable limits, the MG central controller should compensate that.

\section{Case-1: Microgrid performance without any delay}

First, let us assume there is no communication delay $\left(T_{\text {Data- }}\right.$ Frame $=0$ ). It is assumed that the MG is initially in steady-state and autonomous condition, with a total load demand of approximately $0.41 \mathrm{pu}$ where $1 \mathrm{pu}$ is $6 \mathrm{~kW}$. At $t=0.5 \mathrm{~s}$, this load is increased to $1 \mathrm{pu}$ and at $t=1 \mathrm{~s}$, the network load is decreased to $0.53 \mathrm{pu}$. At $t=1.5 \mathrm{~s}$, the load is further decreased to $0.17 \mathrm{pu}$.

The output active power ratio among the two DGs, is maintained as 1:2, as assigned by the central controller (Fig. 8a) for all load changes (Fig. 8b). The MG voltage and frequency are within the acceptable limits during all load changes (Fig. $8 \mathrm{c}-\mathrm{d})$. Hence, the central controller does not issue any control commands and $V_{\text {rated }}$ is kept as $1 \mathrm{pu}$ while the reference frequency $\left(f_{\text {rated }}\right)$ is kept as $50 \mathrm{~Hz}$ (Fig. 8e-f).

\section{Case-2: Droop control within the MG central controller}

In Section II, it was proposed that the droop control should be located within the outer-loop of the primary controller of each DG. If the droop control is considered as a module of the MG central controller, a data communication system is required to transfer output $P$ and $Q$ of each DG to the central controller and return the $|V|$ and $\delta$ instantaneously, as required by (4). The receiver in the central controller receives only one data at a time and is not a parallel operation. Therefore, for the MG system of Fig. 7 which contains 2 DGs and each DG needs to transfer 2 data (i.e. $P$ and $Q$ ) and receive 2 data (i.e. $|V|$ and $\delta$ ), the total communication delay with the fastest ZigBee technology (i.e. $2.45 \mathrm{GHz}$ ) is $2 \mathrm{DG} \times 2$ data transfer $\times 0.112$ $\mathrm{ms}=0.448 \mathrm{~ms}$. The delay will be even higher if $868 \mathrm{MHz}$ or $915 \mathrm{MHz}$ ZigBee are utilized [19].
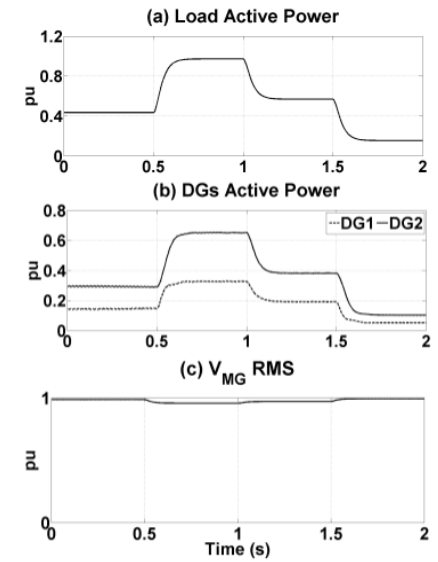

Fig. 8. MG performance without any communication delay.

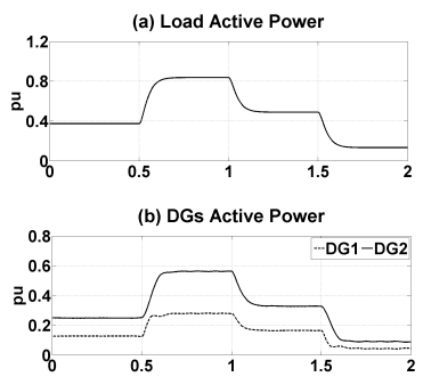

(c) $V_{M G} R M S$

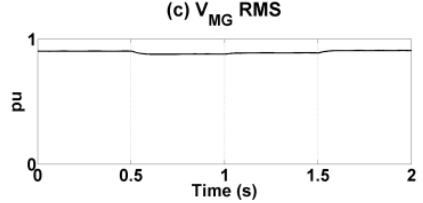

Fig. 10. MG performance assuming $4 \mathrm{~ms}$ communication delay.
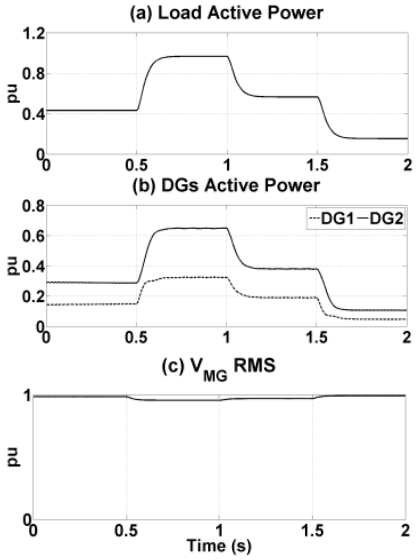

Fig. 9. MG performance assuming $0.5 \mathrm{~ms}$ communication delay.
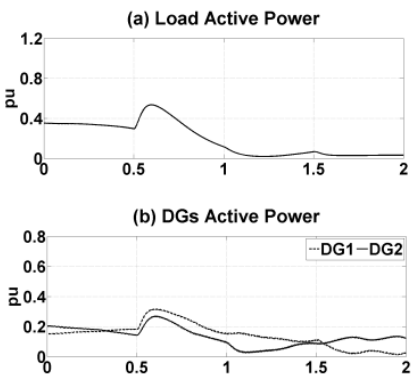

(c) $V_{M G} R M S$

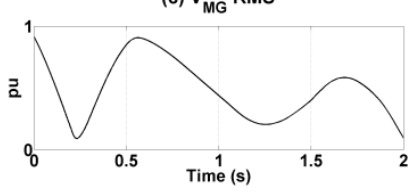

Fig. 11. MG performance assuming $10 \mathrm{~ms}$ communication delay.

Now, a fixed delay of $0.5 \mathrm{~ms}$ is applied in the MG system of Case-1 to transfer $P, Q$ from each DG to the central controller and $|V|$ and $\delta$ from the central controller to each DG. The simulations results are shown in Fig. 9. It can be seen that the considered delay time does not lead to dynamic maloperation of the DGs.

By increasing the delay time to more than $1 \mathrm{~ms}$, dynamic operation of the DGs are affected significantly. As an example, the results of the system with $4 \mathrm{~ms}$ and $10 \mathrm{~ms}$ delay are shown respectively in Fig. 10 and Fig. 11. As it can be seen, the output powers of the DGs and the network voltage magnitude are affected and the system fails to operate as expected.

\section{Case-3: Droop control within the DG primary controller}

As it was demonstrated in Case-2, the dynamic operation of a MG with more than 2 DGs will fail if the droop control is assumed within the MG central controller, due to the high communication delay. Now, let us assume that the droop control is located within the outer-loop of the primary controller of each DG, as proposed in Section II, and the MG central controller is only responsible for regulating the network voltage and frequency within the standard limits, only if they are violated. Let us assume, the voltage magnitude and frequency are only monitored in one place in the MG system. The total 
communication delay for transferring these two data (i.e. $\left|V_{\mathrm{MG}}\right|$ and $\left.f_{\mathrm{MG}}\right)$ from their sensors to the $\mathrm{MG}$ central controller with a $2.45 \mathrm{GHz} \mathrm{ZigBee}$ is 2 data transfer $\times 0.112 \mathrm{~ms}=0.224$ ms [19]. However, as this process has a discrete operation with a larger time step of a few minutes, the communication delay of $0.224 \mathrm{~ms}$ will not affect the system operation.

\section{Case-4: Communication delay from the main $C B$ to the DGs}

As discussed in Section V, the status of the MG main $\mathrm{CB}$ should be immediately transferred to each DG so that the DG can update its operation mode if the MG changes its mode of operation from grid-connected to autonomous and vice versa. Two options can be considered. In the first option, the $\mathrm{CB}$ status is transferred to the MG central controller and the $\mathrm{MG}$ central controller passes this information to the primary controller of each DG. In such a case, the total communication delay for the MG system of Fig. 7 with 2 DGs and $2.45 \mathrm{GHz}$ ZigBee is 1 data $\times 2$ data transfers $\times 0.112 \mathrm{~ms}=0.224 \mathrm{~ms}$ [19]. The second option is assuming a direct data transfer from the MG main CB to the primary controller of each DG. In this case, the total communication delay will be only 0.112 ms for a $2.45 \mathrm{GHz}$ ZigBee [19].

Let us consider the network of Case-1. It is assumed that at the MG is initially in steady-state condition and gridconnected. At $t=0.4 \mathrm{~s}$, the MG main CB opens and it falls into autonomous mode of operation. The system of Case- 1 is simulated assuming a zero and $40 \mathrm{~ms}$ communication delay for transfer of the MG main CB status to the primary controller of the DGs. The results are shown in Fig. 12. Only the network voltage is shown in the simulations. As it can be seen from this figure, the DGs dynamic operation does not fail even for a $40 \mathrm{~ms}$ delay.

\section{CONCLUSIONS}

The requiremenets of the a proper communicatio system is discussed in this paper and a ZigBee-based wireless communication system is proposed as a suitable system for MGs. The proposed communication system is responsible for transmitting several electrical parameters data among the local controller of each DG and the MG central controller as well as the MG main $\mathrm{CB}$ status from the $\mathrm{CB}$ to each DG. Different ZigBee carriers are compared from the communication delay point of view and it is suggested that for MGs distributed in a smaller geographical area, a 2.45 $\mathrm{GHz} \mathrm{ZigBee}$ is more suitable. A MG system is considered and its performance is analysed assuming a constant communication delay for the tranfer of each pararemter. Through the PSCAD/EMTDC-based simulations, it was shown that the droop control system needs to be located as the outer-loop of the primary controller of each DG; otherwise, for MGs with high number of DGs there is a great possibility of system failure due to the communication delays. It was also shown that the communication delay for transferring the setpoits of the droop control from the central controller and the MG main $\mathrm{CB}$ status to the primary controller of each DG does not affect the dynamic performance of the MG system.
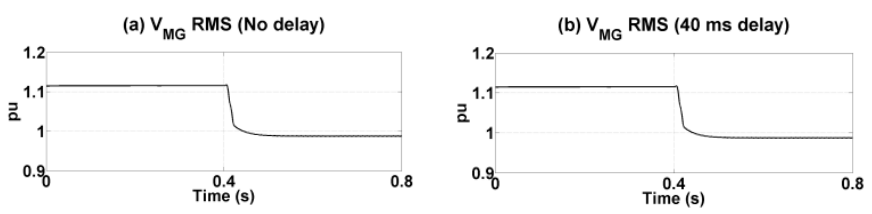

Fig. 12. MG performance assuming a zero and $40 \mathrm{~ms}$ communication delay for transferring the MG main CB status to the primary controller of DGs.

\section{REFERENCES}

[1] R.H. Lasseter, "Microgrids and distributed generation", Journal of Energy Engineering, vol. 133, no. 3, pp. 144-149, Sept. 2007.

[2] S. Yoon, S. Jang, S. Member, and Y. Kim, "Opportunistic Routing for Smart Grid With Power Line Communication Access Networks," IEEE Trans. on Smart Grid, vol. 5, no. 1, pp. 303-311, 2014.

[3] C. Zhang, W. Ma, and C. Sun, "A switchable high-speed fiber-optic ring net topology and its method of high-performance synchronization for large-capacity power electronics system," Int. J. Electr. Power Energy Syst., vol. 57, pp. 335-349, May 2014.

[4] N. Radhika and V. Vanitha, "Smart Grid Test Bed Based on GSM," Procedia Eng., vol. 30, no. 2011, pp. 258-265, Jan. 2012.

[5] A. Usman and S. H. Shami, "Evolution of Communication Technologies for Smart Grid applications," Renew. Sustainable Energy Review, vol. 19, pp. 191-199, Mar. 2013.

[6] F. Gómez-cuba, S. Member, R. Asorey-cacheda, and F. J. Gonzálezcastaño, "Smart Grid Last-Mile Communications Model and Its Application to the Study of Leased Broadband," IEEE Trans. on Smart Grid, vol. 4, no. 1, pp. 5-12, 2013.

[7] Y. Zhang, L. Wang, W. Sun, et al., "Distributed Intrusion Detection System in a Multi-Layer Network Architecture of Smart Grids," IEEE Trans. on Smart Grid, vol. 2, no. 4, pp. 796-808, Dec. 2011.

[8] T. Liu, Y. Liu, Y. Mao, et al., "A Dynamic Secret-Based Encryption Scheme for Smart Grid Wireless Communication," IEEE Trans. on Smart Grid, vol. 5, no. 3, pp. 1175-1182, May 2014.

[9] N. Langhammer and R. Kays, "Performance Evaluation of Wireless Home Automation Networks in Indoor Scenarios," IEEE Trans. Smart Grid, vol. 3, no. 4, pp. 2252-2261, Dec. 2012.

[10] N.C. Batista, R. Melício, J.C.O. Matias, and J.P.S. Catalão, "Photovoltaic and wind energy systems monitoring and building/home energy management using ZigBee devices within a smart grid," Energy, vol. 49, pp. 306-315, Jan. 2013.

[11] S. Ahmad, "Smart metering and home automation solutions for the next decade," International Conference on Emerging Trends in Networks and Computer Communications (ETNCC), 2011, pp. 200-204.

[12] C. Deng, X. Xiao, Z. Fu, et al., "Terrestrial-Satellite Hybrid Backbone Communication Network for Smart Power Grid," Energy Procedia, vol. 12, pp. 27-36, Jan. 2011.

[13] F. Shahnia, R.P.S. Chandrasena, et al., "Primary control level of parallel distributed energy resources converters in system of multiple interconnected autonomous microgrids within self-healing networks," IET Gener. Transm. Distrib., vol. 8, no. 2, pp. 203-222, 2014.

[14] I. Serban and C. Marinescu, "Control Strategy of Three-Phase Battery Energy Storage Systems for Frequency Support in Microgrids and with Uninterrupted Supply of Local Loads," IEEE Trans. Power Electronics, vol. 29, no. 9, pp. 5010-5020, 2014.

[15] X. Lu, S. Member, et al., "An Improved Droop Control Method for DC Microgrids Based on Low Bandwidth Communication With DC Bus Voltage Restoration and Enhanced Current Sharing Accuracy," IEEE Trans. on Power Electronics, vol. 29, no. 4, pp. 1800-1812, 2014.

[16] XBee/XBee-PRO ${ }^{\circledR} R F$ Modules. Digi International Inc., 2009.

[17] IEEE Standards 802.15.4, IEEE Computer Society, 2003, pp. 1-679.

[18] R.P.S. Chandrasena, F. Shahnia, A. Ghosh and S. Rajakaruna, "Secondary Control in Microgrids for Dynamic Power Sharing and Voltage/Frequency Adjustment," $24^{\text {th }}$ Australasian Universities Power Engineering Conference (AUPEC), Sep. 2014.

[19] M.A. Setiawan, F. Shahnia, et al., "Developing the ZigBee based data payload coding for data communication in microgrids," $24^{\text {th }}$ Australasian Universities Power Engineering Conference (AUPEC), Sep. 2014. 